\title{
Preparation of diamond like carbon thin film on stainless steel and its SEM characterization
}

\author{
KAMLESH KUMARI ${ }^{\dagger \dagger}$, S BANERJEE ${ }^{\dagger}$, T K CHINI ${ }^{\dagger}$ and N R RAY* \\ Plasma Physics Division, ${ }^{\dagger}$ Surface Physics Division, Saha Institute of Nuclear Physics, \\ Kolkata 700 064, India \\ ${ }^{\dagger \dagger}$ Amity Institute of Nanotechnology, Amity University, Noida 201 303, India
}

MS received 28 October 2008

\begin{abstract}
We report the formation of a very smooth, continuous and homogeneous diamond-like carbon DLC thin coating over a bare stainless steel surface without the need for a thin $\mathrm{Si} / \mathrm{Cr} / \mathrm{Ni} / \mathrm{Mo} / \mathrm{W} / \mathrm{TiN} / \mathrm{TiC}$ interfacial layer. As confirmed by the field-emission scanning electron microscopy, good adhesion is achieved as characterized by (i) the formation of a smooth, continuous film with no pores, (ii) a significant reduction of oxygen in the interfacial layer, and (iii) the development of rich carbon content at the top surface. Thickness measurements by cross-sectional secondary-emission microscopy showed that the DLC coating is essentially a 2-dimensional material.
\end{abstract}

Keywords. Diamond-like carbon; buffer layer; plasma CVD; surface characterization; biomedical applications.

\section{Introduction}

In medicine, implants such as hip and knee joints, coronary stents, heart valves, and intra-ocular lenses are exposed to cells and fluids within the body and could experience corrosion. Bodily fluids contain $\sim 1 \%$ sodium chloride $\mathrm{NaCl}$, which provides a corrosive environment for these implants. Furthermore, joint implants are exposed to sliding wear, which can potentially cause adverse effects within the body due to the interaction of released metal ions from the implants with tissues and cells. A detailed review of materials used in human implants can be found elsewhere (Tiainen 2001). In many cases, coating the implants with protective films, which can reduce corrosion and wear, may prevent or alleviate the problems described above and extend the lifetime of the implants to benefit the patients.

Diamond-like carbon (DLC), which is characterized by its chemical inertness, corrosion and wear resistance (Grill and Meyerson 1994), is a suitable coating material for such purposes. Although its use for protecting implants has been suggested since the early 1990s (Butter and Lettington 1995; Jacobs et al 1995), only in recent years it has attracted considerable interest in biomedical applications due to its inherent biocompatibility. In this application, DLC is typically used as nanocrystalline diamond films, either in pure form or as nanocomposites

*Author for correspondence (niharranjan.ray@saha.ac.in) of diamond nanocrystallites embedded in an amorphous carbon matrix (NCD/a-C) (Popov 2007). However, most of the work on $\mathrm{NCD} / a-\mathrm{C}$ films reported in the literature has been performed on silicon substrates (Bhattacharyya et al 2001; Popov et al 2003; Ray and Iyengar 2006).

Steel is the predominant material of construction in modern hygienic design of biomedical and food processing equipment (Muller 2007). One of the attributes of steel is that it forms an oxide layer on its surface. This layer exists in the form of chromium oxide $\left(\mathrm{Cr}_{2} \mathrm{O}_{3}\right)$ and provides corrosion resistance to the steel surface. Additionally, this layer passivates the steel surface and reduces the issues associated with coating DLC over steel. Adding a suitable interfacial layer (Grill et al 1988; Ong and Chang 1991; Shih 1993; Fayer et al 1995), such as a thin layer of $\mathrm{Si} / \mathrm{Cr} / \mathrm{Ni} / \mathrm{Mo} / \mathrm{W} / \mathrm{TiN} / \mathrm{TiC}$ between the bare steel and DLC coating, can greatly improve the adhesion between DLC and steel. Formation of a buffer layer in between the DLC coating and the substrate material (Grill et al 1988; Ong and Chang 1991; Shih 1993; Fayer et al 1995) may influence bioproperties of the NCD/a-C thin films (Okroj et al 2006; Popov et al 2007). Bioproperties are influenced by many factors, including good adhesion, continuity, homogeneity, smoothness of the film, and composition of $s p^{2}$ and $s p^{3}$ carbon atoms in the composite films.

The purpose of this work is to study the adhesion of DLC coating over bare steel surfaces after removal of the chrome oxide layer. The specific procedure that we use involves sputtering of the substrate surface by argon ions 
for removing the oxide layer, pre-treatment of the steel surface by hydrogen plasma, and DLC coating by asymmetric capacitively coupled, radio-frequency discharge, plasma-enhanced chemical vapour deposition (PECVD).

\section{Experimental}

The following sections describe the three main steps used to coat DLC over a bare stainless steel surface.

\subsection{Cleaning of stainless steel}

The first step in cleaning the stainless steel surface $(15 \times 15 \mathrm{~mm})$ was to rinse the surface with caustic soda $(\mathrm{NaOH})$ followed by water. The $\mathrm{NaOH}$ wash removes the polar substances such as oils and fatty acids present on the steel surface. Following the $\mathrm{NaOH}$ wash, the substrate was dipped in nitric acid $\left(\mathrm{HNO}_{3}\right)$ solution to remove any ionic impurities. This was also followed by a water rinse.

\subsection{Sputtering}

After cleaning the stainless steel substrate, the passive chromium oxide layer was removed by argon ion sputtering. The typical conditions used for sputtering were: total pressure $=0.3 \mathrm{mbar}$, flow rate of $\mathrm{Ar}$ gas $=100 \mathrm{sccm}, \mathrm{RF}$ power $=30$ watts, d.c. self-bias $=-(150 \pm 10)$ volts. The time of sputtering was $15 \mathrm{~min}$.

\subsection{Pre-treatment}

Once the sputtering was completed, the steel surface was pre-treated with a hydrogen discharge. The typical conditions for this pre-treatment were: total pressure $=0.3 \mathrm{mbar}$, flow rate of $\mathrm{H}_{2}$ gas $=500 \mathrm{sccm}, \mathrm{RF}$ power $=25$ watts, d.c. self-bias $=-(150 \pm 10)$ volts. The time of pretreatment was $15 \mathrm{~min}$.

\subsection{Deposition of DLC coating over stainless steel}

Deposition of the DLC coating over stainless steel was achieved by asymmetric capacitively coupled radiofrequency discharge plasma-enhanced chemical vapour deposition (PECVD) (Ray and Iyengar 2006). The typical deposition conditions for depositing $\mathrm{NCD} / a-\mathrm{C}$ film on $\mathrm{Si}$ (100) substrate (Singha et al 2006) were used: total pressure $=0.7 \mathrm{mbar}$, flow rate of $\mathrm{He}$ gas $=1500 \mathrm{sccm}$, flow rate of $\mathrm{H}_{2}$ gas $=500 \mathrm{sccm}$, flow rate of $\mathrm{CH}_{4}$ gas $=50 \mathrm{sccm}$, $\mathrm{RF}$ power $=50$ watts, d.c. self-bias $=-(200 \pm 10)$ volts. The time of deposition was $25 \mathrm{~min}$.

Helium $(\mathrm{He})$ plasma energy was used to provide the activation energy to dissociate $\mathrm{H}_{2}$ and $\mathrm{CH}_{4}$ molecules, which led to the formation of reactive particles such as atoms, ions and free radicals. Beyond the activation stage, these reactive particles continued to mix and undergo a complex set of chemical reactions before they impinged onto the surface of the substrate.

After removal of the oxide layer by sputtering, pretreatment of the substrate by hydrogen discharge was critical as the surface treatment with atomic hydrogen was a precursor to successful coating. Specifically, the atomic hydrogen attaches to the nucleation site and reacts with neutral species such as $\mathrm{CH}_{4}$ to create reactive radicals such as $\mathrm{CH}_{3}$, which can then attach to suitable surface sites.

Visual inspection, following the completion of the deposition process, showed the formation of a scratchresistant, hard, and gold-coloured thin film over the steel plate.

\section{Characterization by secondary electron microscopy (SEM)}

The characterization of the DLC-coated stainless steel was done by using a FEI QUANTA 200F SEM (FESEM). An Everhart-Thornley Detector (ETD) was used as the secondary electron detector.

\subsection{Topographic images}

The SEM micrographs in figures $1 \mathrm{a}$ and $\mathrm{b}$ show that the thin DLC film had a smooth, continuous surface (indicating good adhesion between DLC and stainless steel) and was almost devoid of any roughness. Figure la shows the surface morphology of the DLC film with electron acceleration at $2 \mathrm{kV}$ and a magnification on the order of $20 \mathrm{kX}$.

Figure $1 \mathrm{~b}$ shows the surface morphology of the same DLC film with electron acceleration at $2 \mathrm{kV}$ but with a magnification of the order of $80 \mathrm{kX}$. Even at such a high magnification, we did not observe any particulate-like surface. Therefore, it can be concluded that the thin DLC film was smooth, continuous, and non-porous. Upon increasing the applied accelerating potential from $2 \mathrm{kV}$ to $10 \mathrm{kV}$ and changing the magnification to $20 \mathrm{kX}$, the surface morphology showed random orientations of grains with different sizes (figure 2a).

This observation was attributed to the scattering behaviour of the electrons as a function of the applied voltage. As the applied potential of the electron increases, the interaction volume of the electrons within the specimen (here DLC film) increases. As a result, less surface morphology is obtained. The SEM image of the bare steel (figure $2 \mathrm{~b}$ ) with electron acceleration at $10 \mathrm{kV}$ and a magnification of the order of $20 \mathrm{kX}$ shows the presence of scratches and abrasions on the bare steel surface. Therefore, the random orientation of grains with different sizes as observed in the SEM image of the coated 

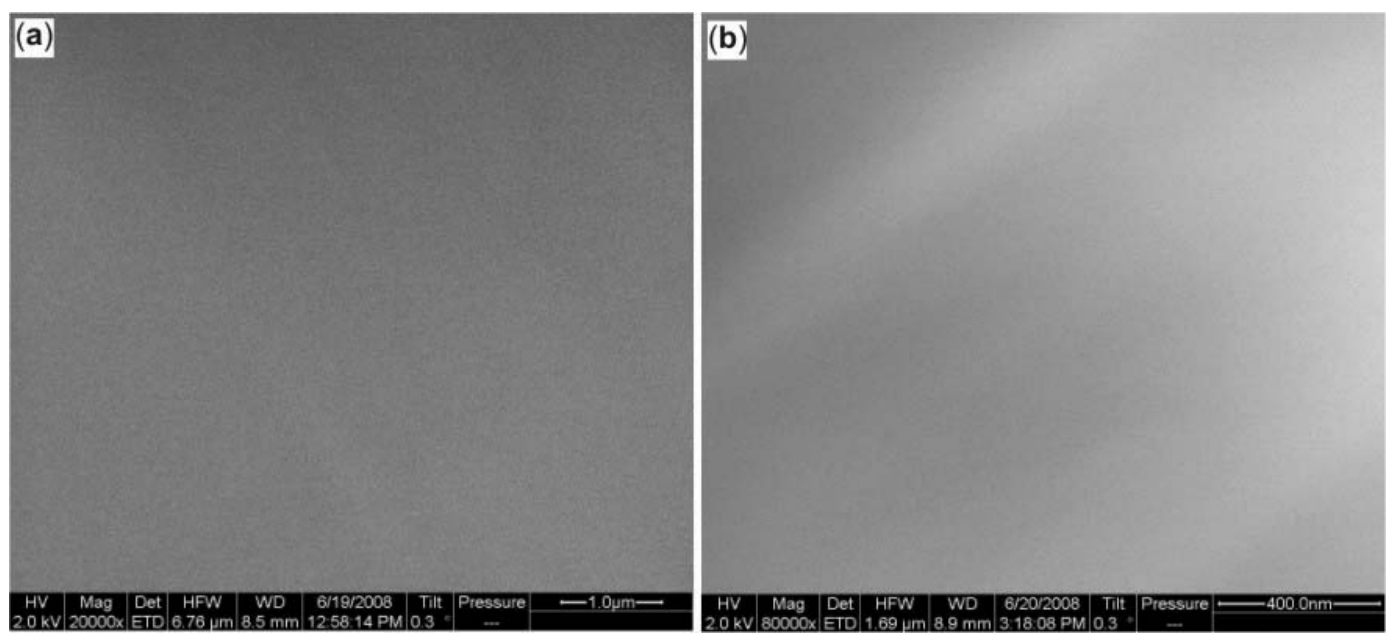

Figure 1. Typical SEM images of a. DLC film with electron acceleration at $2 \mathrm{kV}$ and a magnification of $20 \mathrm{kX}$ and $\mathbf{b}$. a magnification of $80 \mathrm{kX}$.
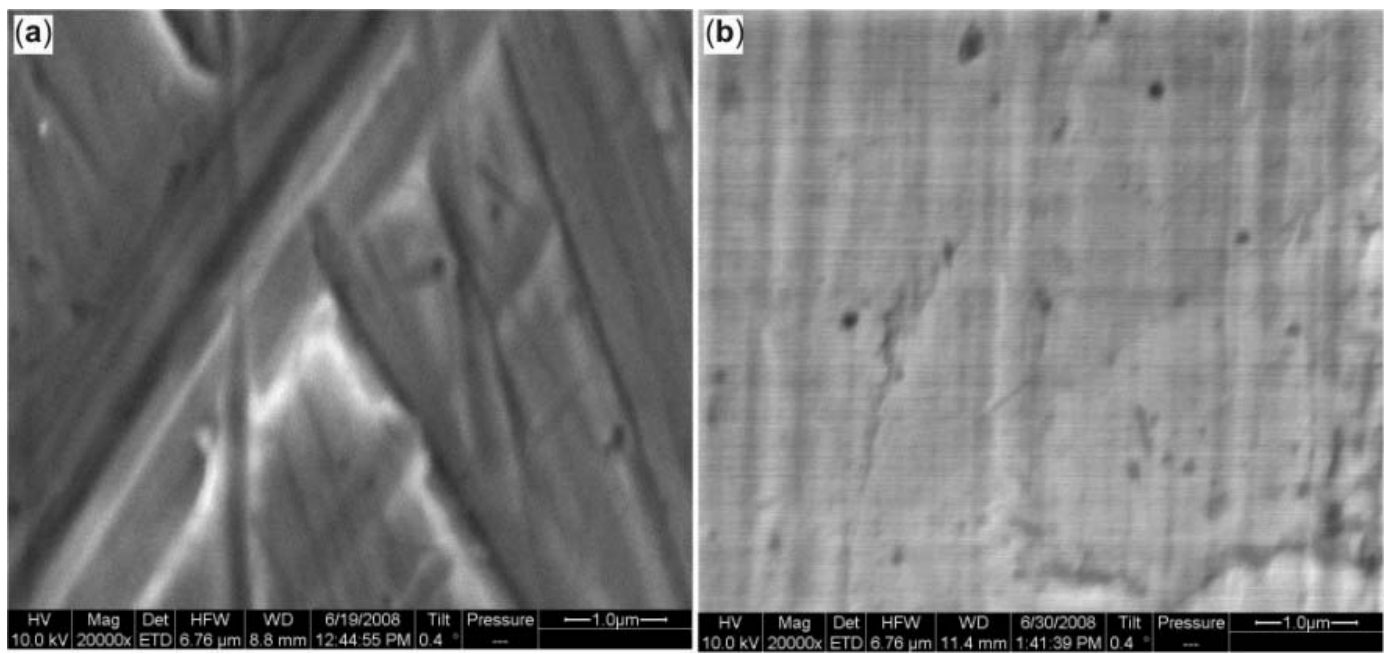

Figure 2. Typical SEM images of a. DLC film with electron acceleration at $10 \mathrm{kV}$ and a magnification of $20 \mathrm{kX}$ and $\mathbf{b}$. bare steel with electron acceleration at $10 \mathrm{kV}$ and a magnification of $20 \mathrm{kX}$.

stainless steel (figure 2a) should be due to the presence of scratches and abrasions on the bare stainless steel substrate.

Cross-sectional SEM (XSEM) images were taken to measure the thickness of DLC films. At an applied voltage of $10 \mathrm{kV}$ and a magnification of $28 \mathrm{kX}$, the DLC film was found to be homogeneous and continuous (figure 3). Some of the discontinuities seen in the micrographs are attributed to the scratches and abrasions present in the stainless steel. Based on the XSEM image in figure 3, the thickness of the DLC thin film was determined to be $555 \pm 25 \mathrm{~nm}$.

\subsection{Backscattered images}

During the XSEM imaging, the backscattered images were also collected using a solid state detector (SSD).
The elements with higher atomic number, i.e. stainless steel, appeared brighter in colour, while coated carbon (low atomic number) appeared darker or grey in colour. At the applied voltage of $10 \mathrm{kV}$ and a magnification of $28 \mathrm{kX}$, the image (figure 4) was obtained using backscattered electrons.

\subsection{EDX analysis}

Elemental composition of the thin DLC film was determined using energy dispersive X-ray analysis (EDX). The energy of the exciting electron beam for EDX analysis in the experiment was $18 \mathrm{keV}$, with a magnification of $1 \mathrm{kX}$.

The typical EDX spectrum of the bare stainless steel is shown in figure $5 \mathrm{a}$. 
The spectrum showed that bare stainless steel consists mainly of iron $(\mathrm{Fe})$, chromium $(\mathrm{Cr})$, manganese $(\mathrm{Mn})$ and nickel (Ni), with small traces of carbon (C) and silicon (Si). It also contains oxygen in the form of passive chromium oxide $\left(\mathrm{Cr}_{2} \mathrm{O}_{3}\right)$ layer present on the top layer. The EDX spectrum of the stainless steel coated with thin DLC film is shown in figure $5 \mathrm{~b}$. We can make the following observations from comparisons of the EDX spectrum of the bare stainless steel (figure 5a) with the thin DLC-

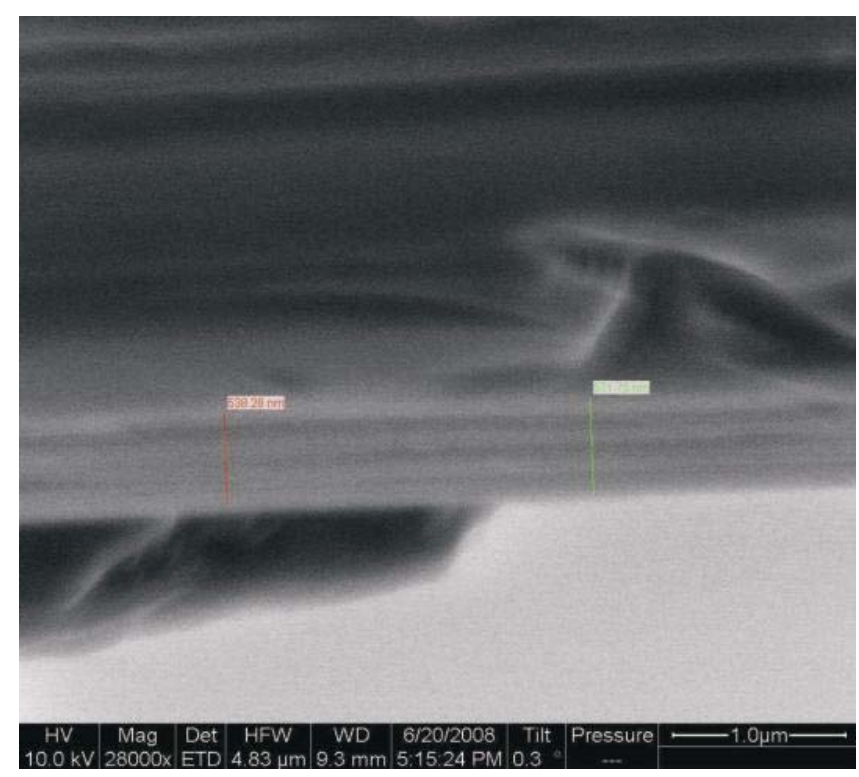

Figure 3. Typical cross-sectional SEM image of DLC film with electron acceleration at $10 \mathrm{kV}$ and a magnification at $28 \mathrm{kX}$.

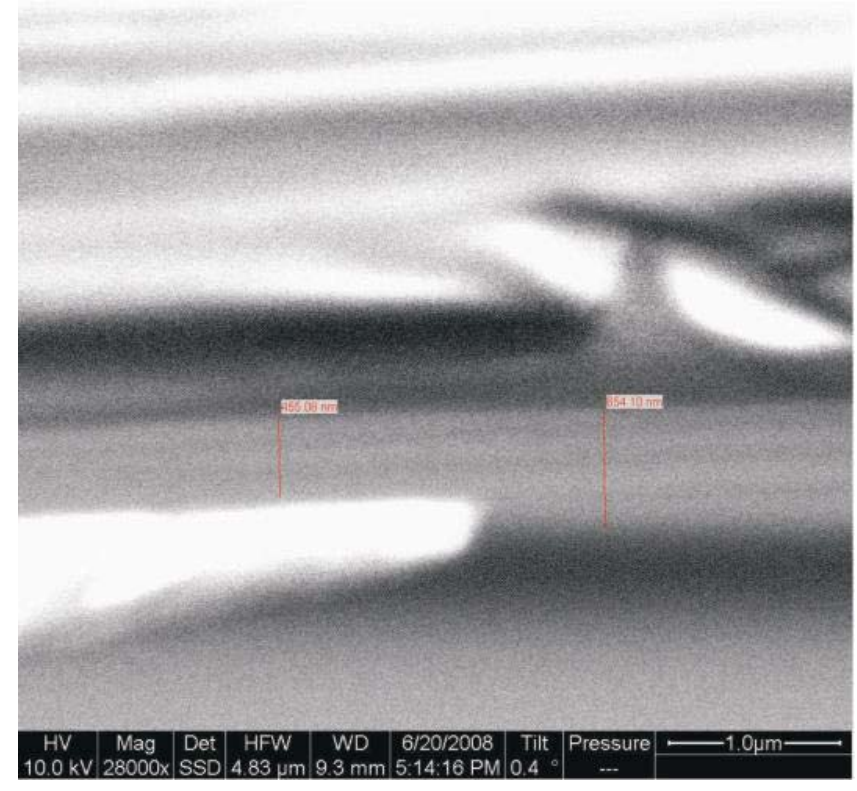

Figure 4. Typical backscattered SEM image of DLC film with electron acceleration at $10 \mathrm{kV}$ and a magnification at $28 \mathrm{kX}$. coated stainless steel (figure 5b): (i) the oxygen present in the form of $\mathrm{Cr}_{2} \mathrm{O}_{3}$ layer onto the stainless steel was removed by sputtering before the deposition of DLC film onto stainless steel, and (ii) the main element in the film is carbon, as seen by the much higher carbon content in the DLC film than in the bare stainless steel.

\section{Results and discussion}

The SEM images at low electron acceleration voltage $(2 \mathrm{kV})$ showed typical top surface features of the thin DLC film, which is characterized as a uniform, smooth, and continuous surface with no observable porosity.

The above results confirmed our ability to obtain good adhesion between the DLC film and steel. These results include (i) the deposition of a smooth, continuous film with no porosity, (ii) a significant reduction of oxygen in
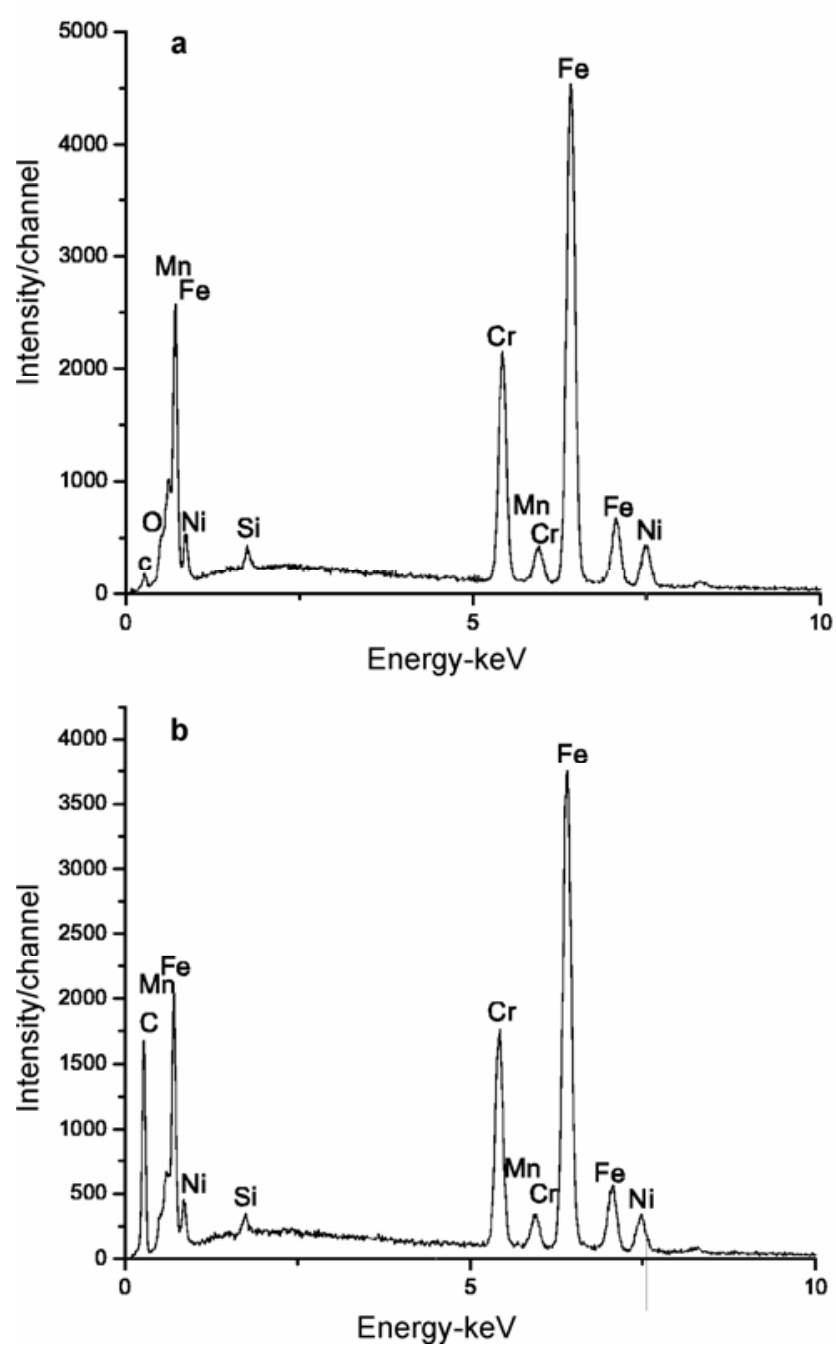

Figure 5. Typical EDX spectra of a. bare steel and b. steel coated with DLC thin film. 
the interfacial layer, and (iii) the formation of a carbonrich composition at the top surface.

\section{Conclusions}

We have reported, for the first time, the formation of a very smooth, continuous and homogeneous DLC thin coating onto a bare stainless steel surface without the need for a thin $\mathrm{Si} / \mathrm{Cr} / \mathrm{Ni} / \mathrm{Mo} / \mathrm{W} / \mathrm{TiN} / \mathrm{TiC}$ interfacial layer. Good adhesion of DLC coating to the bare steel surface was achieved and confirmed by the FESEM characterization results, which showed a smooth, continuous film with no porosity, significant reduction in oxygen content at the interfacial layer, and rich carbon content at the top surface. Thickness measurement by XSEM showed that the DLC coating was essentially a 2-dimensional material.

Steel coated with a thin DLC film can be used for biomedical applications, provided that the film is biocompatible. The biocompatibility of the DLC thin film will be investigated in the future.

\section{Acknowledgements}

Authors thank Mr Dipankar Das and Mr Sib Sankar Sil for technical assistance and $\mathrm{Mr}$ Abhijit Betal and $\mathrm{Mr}$ Amalendu Bal for scientific assistance in the work.

\section{References}

Butter R S and Lettington A H 1995 Applications of diamond films and related materials, Third international conference (Washington DC: NIST Special Publication) 885 p. 683 Bhattacharyya S et al 2001 Appl. Phys. Lett. 791441

Fayer A et al 1995 Appl. Phys. Lett. 672299

Grill A and Meyerson B S 1994 Development and status of diamond like carbon, in Synthetic diamond: emerging CVD science and technology (eds) K E Spear and J P Dismukes (New York: Wiley) Ch. 5

Grill A et al 1988 J. Mater. Res. 3214

Jacobs T L et al 1995 Applications of diamond films and related materials, Third international conference (Washington DC: NIST Special Publication) 885 p. 753

Muller R R 2007 Trends Food Sci. \& Technol. 18 S112

Ong T P and Chang R P H 1991 Appl. Phys. Lett. 58358

Okroj W et al 2006 Dia. \& Relat. Mater. 151535

Popov C et al 2003 in Proceedings of the CVD XVI and EUROCVD-14 conference (eds) M Allendorf et al (Pennington, N J: The Electrochemical Society), Vol. 08, p. 1079

Popov C et al 2007 Dia. \& Relat. Mater. 16 735, 740

Ray N R and Iyengar A N S 2006 in Proceedings of the sixth international conference on reactive plasmas and $23 \mathrm{rd}$ symposium on plasma processing (ICRP-6/SPP-23) (eds) $\mathrm{R}$ Hatakeyama and S Samukawa (Sendai, Japan: Matshushima) p. 583

Singha A 2006 J. Appl. Phys. 10004410

Shih H C et al 1993 Surf. Coat. Tech. 57197

Tiainen V M 2001 Dia. Relat. Mater. 10153 